\title{
Surgical Retrieval of Fractured Orthodontic Mini-implant: A Case Report
}

\author{
Elsie S Ebenezer ${ }^{1}$, Gowtham Krishna ${ }^{2}$, Srinivasan $\mathrm{K}^{3}$, Saravana Kumar Ravindran ${ }^{4}$, Pratebha Balu ${ }^{5}$, Karthikeyan Ilangovan ${ }^{6}$
}

\begin{abstract}
Aim: This case report demonstrates the successful retrieval of orthodontic mini-implant.

Background: The idea of absolute anchorage has always been an evasive goal for clinicians. Tooth movements that are arduous to move can be achieved by orthodontic mini-implants or temporary anchorage devices. Since 1997, there is plenty of evidence available on mini-screw implant placement, which has been used for anchorage. But ample of evidence exists on how to use the anchoraging systems, and their failures have been merely focused upon, especially mini-implant fracture.

Case description: Two case reports of mini-implant fracture on 45, 46 regions and one case report on 25,26 regions are been discussed. A $1.6 \times 8 \mathrm{~mm}$ stainless steel mini-implant (Ortho One) was used as a temporary anchorage device. The probable cause of mini-implant fracture was the improper angulation of mini-implant during placement and thick cortication of bone. After attaining adequate anesthesia, the surrounding bone was removed circumferentially using carbide bur under copious saline irrigation. With the help of Howe's plier, the mini-implant is retrieved. After achieving hemostasis, simple interrupted sutures are placed. Postoperative instructions, antibiotics, and analgesics are prescribed.

Conclusion: Anchoraging devices fracture is an unusual clinical presentation and has to be treated wisely. A meticulous understanding of the biological and mechanical properties of anchoraging systems and clinical experience should be important in circumventing the clinical complications.

Clinical significance: Mini-screws are valuable tools that increase and improve the quality of orthodontic treatment if properly used. There is hardly any evidence of fractured mini-implant case reports on it. The subsequent case report marked out the successful management of fractured mini-implant. It is a rare clinical chance that has to be managed judiciously. A methodical understanding of the biological and mechanical aspects of anchoraging systems would be helpful in bypassing complications.
\end{abstract}

Keywords: Fracture, Mini-implants, Orthodontics, Temporary anchoraging systems.

Journal of Scientific Dentistry (2021): 10.5005/jp-journals-10083-1004

\section{BACKGROUND}

Unintentional and careless use of microimplants has shown up implant fracture as a major drawback. The amount of torque given during the mini-implant placement determines the fracture of mini-implant. Since mandible has a higher cortical bone density that eventually increases the torque insertion. The ideal toque value for self-drilling mini-implant is $3-10 \mathrm{~N} \mathrm{~cm} .{ }^{1}$ D2 and D3 are ideal for the self-drilling mini-implant. ${ }^{2,3}$

\section{Case Description}

\section{Case 1}

A 22-year-old male patient was referred from the department of orthodontics to the outpatient department of periodontics for the retrieval of fractured mini-implant in relation to 46 regions. He was diagnosed with angle class I malocclusion bimaxillary protrusion. Group A anchorage was used. A $1.6 \times 8 \mathrm{~mm}$ stainless steel miniimplant (Ortho One) was used as a temporary anchorage device (TAD). Moreover, $8 \mathrm{~mm}$ of fractured mini-implant is encountered during placement. Due to the presence of dense cortical bone, the mini-implant was fractured. It was planned to surgically remove the fractured mini-implant. Informed consent was obtained from the patient. Adequate anesthesia is injected into the region and a full-thickness flap was reflected in 45,46 regions. The fractured mini-implant site was identified and located. (Fig. 1) shows the site of fractured mini-implant. Moreover, 2-3 mm of bone was
${ }^{1}$ Department of Periodontology and Implantology, Indira Gandhi Institute of Dental Sciences, Puducherry, India

${ }^{2,4-6}$ Department of Periodontology, Indira Gandhi Institute of Dental Sciences, Puducherry, India

${ }^{3}$ Department of Periodontology and Implant Dentistry, Indira Gandhi Institute of Dental Sciences, Puducherry, India

Corresponding Author: Elsie $\mathrm{S}$ Ebenezer, Department of Periodontology and Implantology, Indira Gandhi Institute of Dental Sciences, Puducherry, India, Phone: +91 7339625654, e-mail: elsiesunitha@gmail.com

How to cite this article: Ebenezer ES, Krishna G, Srinivasan K, Ravindran SK, Balu P, Ilangovan K. Surgical Retrieval of Fractured Orthodontic Mini-implant: A Case Report. J Sci Den 2021;11(2):56-60.

Source of support: Nil

Conflict of interest: None

circumferentially removed around the fractured site with a carbide bur under generous saline irrigation (Fig. 2). With the help of Howe's plier, the fractured mini-implant was held and removed (Fig. 3). After achieving hemostasis, the site was irrigated with saline. The flap was approximated using simple interrupted sutures (5-0 black braided silk, Ethicon, USA). Coe-Pak is given above the sutures as shown in (Fig. 4). Postoperative antibiotics and analgesics were advised. One week following satisfactory healing, the sutures were removed and again the mini-implant was loaded for function (Fig. 5). 


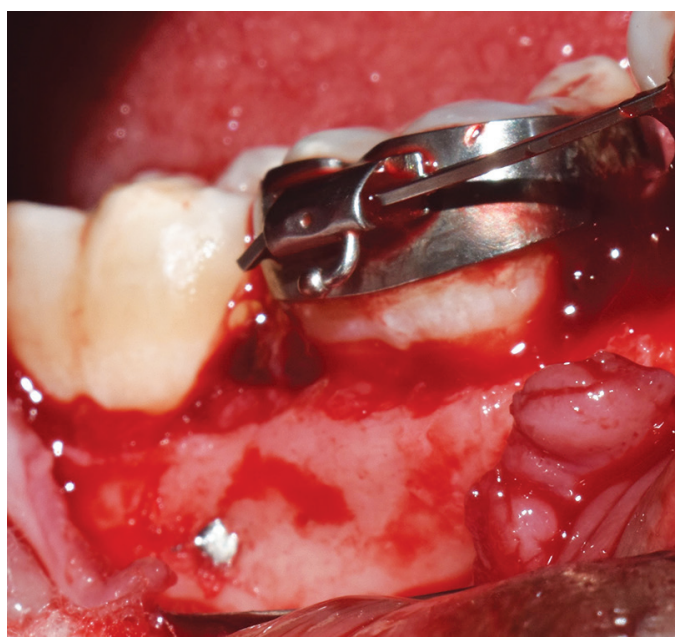

Fig. 1: Fractured mini-implant in relation to 47,46

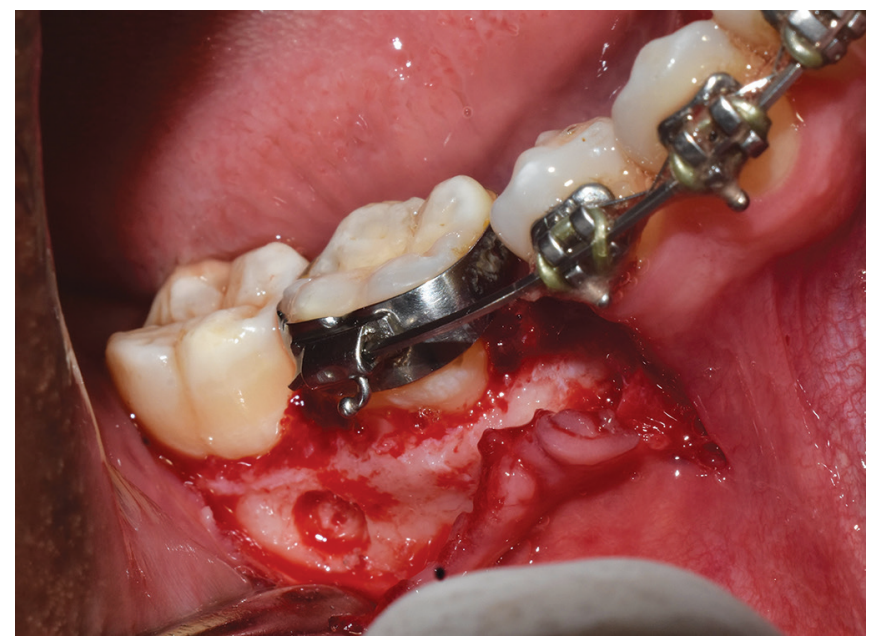

Fig. 2: Bone was circumferentially removed around TAD with a carbide bur

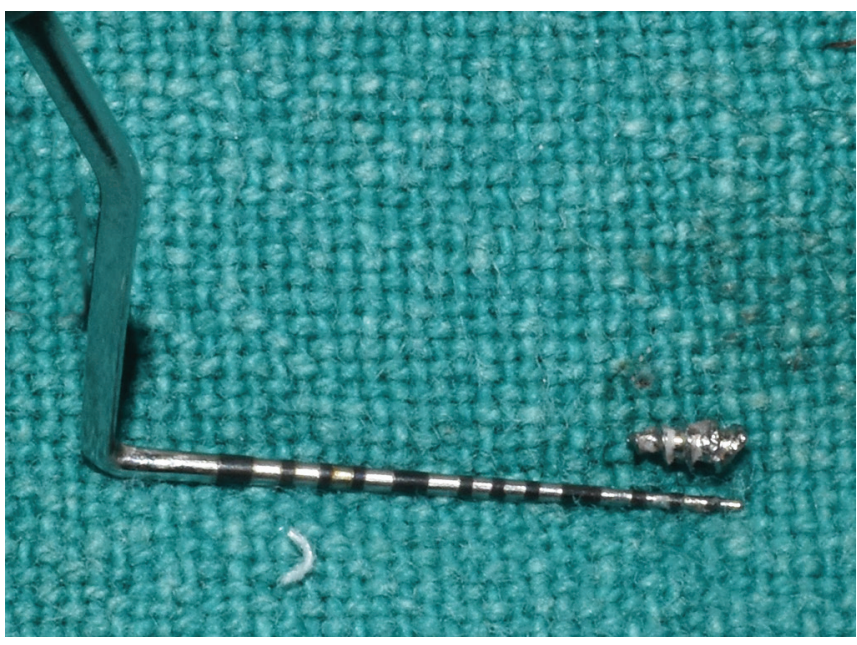

Fig. 3: Retrieved mini-implant

\section{Case 2}

A 23-year-old female patient was referred from the department of orthodontics to the outpatient department of periodontics for

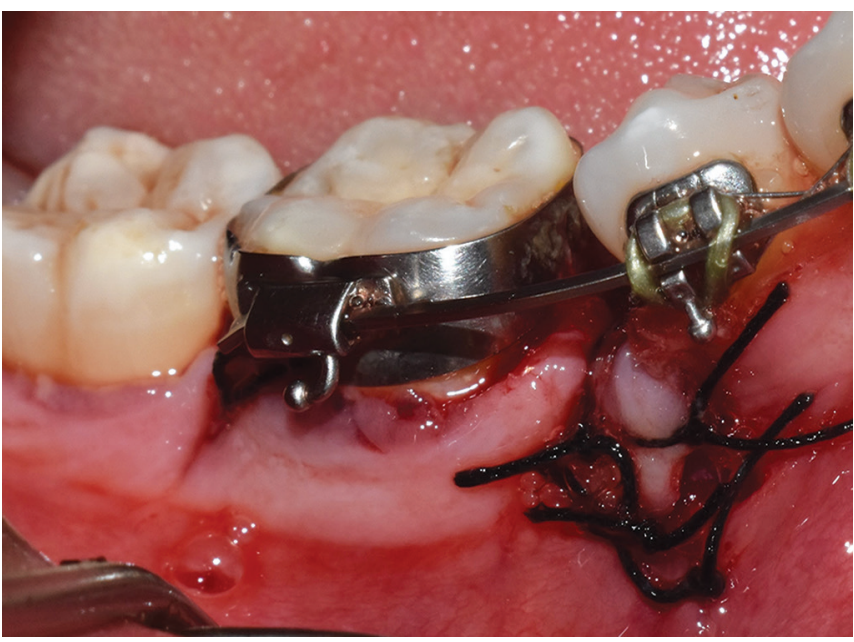

Fig. 4: Simple interrupted suturing is done in relation to 45,46

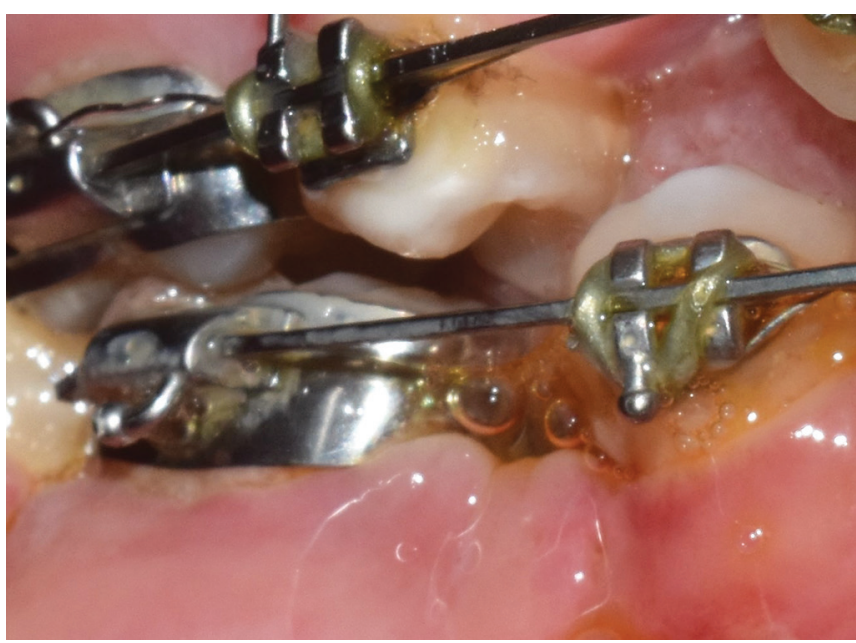

Fig. 5: Postoperative healing after 1 week

the retrieval of fractured mini-implant in relation to 46 regions. She was diagnosed with angle class I malocclusion with anterior open bite. Group A anchorage was used. A $1.6 \times 8 \mathrm{~mm}$ stainless steel mini-implant (Ortho One) was used as a TAD. And $8 \mathrm{~mm}$ of fractured mini-implant was evident during placement of miniimplant. Improper angulation during placement was found to be the cause of fractured mini-implant. It was planned surgically to remove the mini-implant. Informed consent was obtained from the patient. Adequate anesthesia is given in that region and a fullthickness mucoperiosteal flap was reflected in 45,46 regions. The fractured mini-implant anchoring device site was identified and located as shown in (Fig. 6), and $1 \mathrm{~mm}$ of bone was circumferentially removed around the mini-implant region with a carbide bur under copious saline irrigation (Fig. 7). With the help of Howe's plier, the fractured mini-implant was held and removed (Fig. 8). After achieving hemostasis, the site was irrigated with saline. The flap was approximated using simple interrupted sutures (5-0 black braided silk, Ethicon, USA). Coe-Pak is given above the sutures. Postoperative antibiotics and analgesics were advised. One week following satisfactory healing, the sutures were removed and again the mini-implant was loaded for function. 


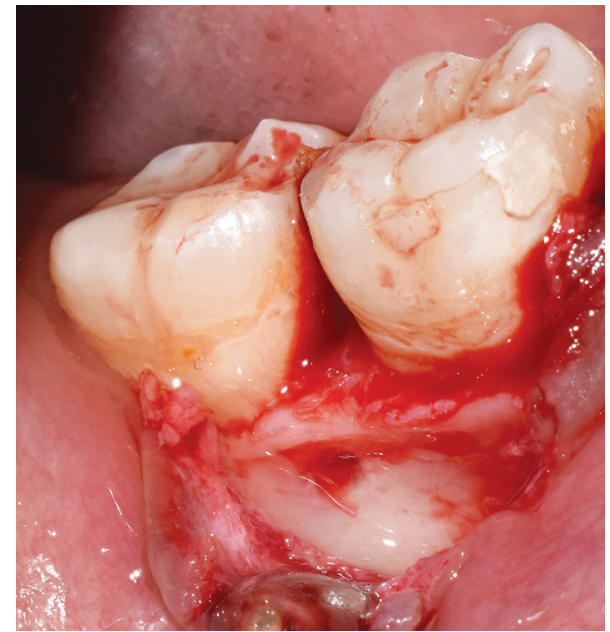

Fig. 6: Fractured mini-implant in relation to 47,46

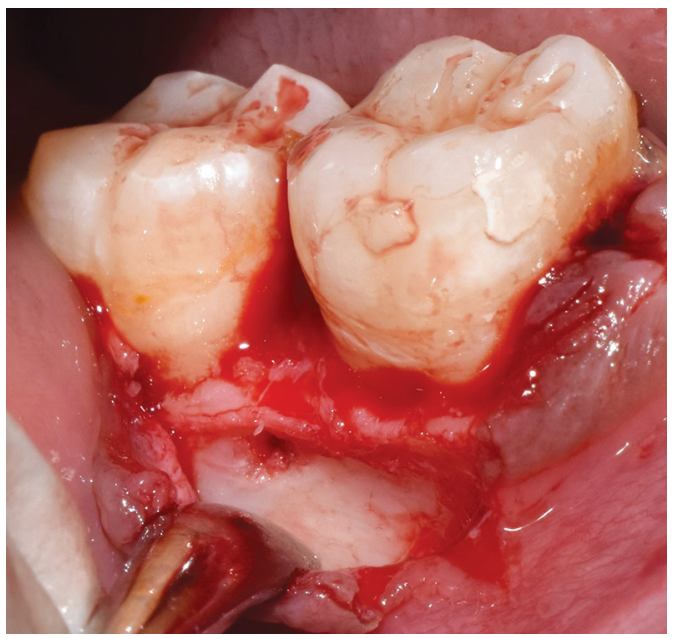

Fig. 7: One millimeter of bone was circumferentially removed around TAD with a carbide bur

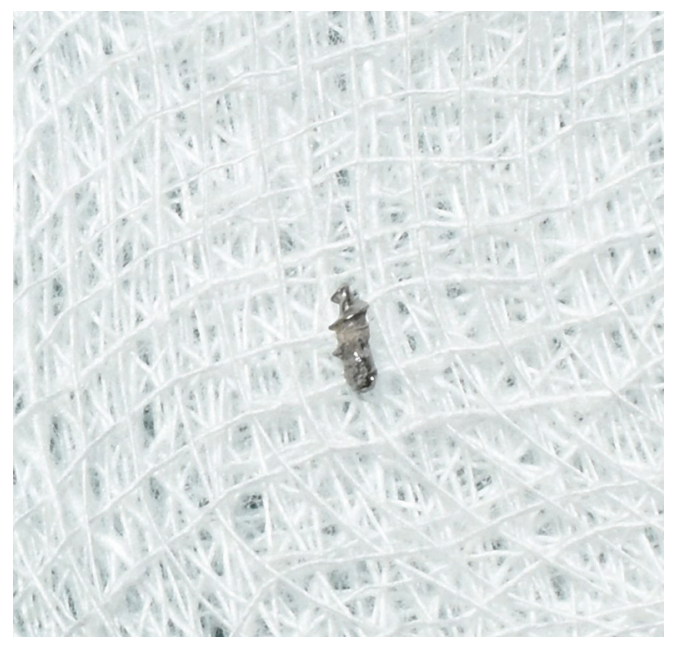

Fig. 8: Retrieved mini-implant

\section{Case 3}

A 24-year-old female patient was referred from the department of orthodontics to the outpatient department of periodontics for the removal of fractured mini-implant in relation to 26,27 regions. She was diagnosed with angle class I malocclusion bimaxillary protrusion. Group A anchorage was used. It was planned to use min-implant as TAD for retraction. A $1.6 \times 8 \mathrm{~mm}$ stainless steel mini-implant (Ortho One) was used. Moreover, $8 \mathrm{~mm}$ of fractured mini-implant was found to be placed in 26,27 regions. The presence of thick cortical bone caused the fracture of mini-implant. It was planned surgically to remove the mini-implant. Informed consent was obtained from the patient. Adequate anesthesia is injected into the site and a full-thickness mucoperiosteal flap was reflected in 26, 27 regions. The fracture mini-implant site was identified and located as shown in (Fig. 9), and $1 \mathrm{~mm}$ of bone was circumferentially removed around the fractured site with a carbide bur under generous saline irrigation (Fig. 10). With the help of Howe's plier, the fractured mini-implant was held and the broken end is removed (Fig. 11). After achieving hemostasis, the site was irrigated with saline. The flap was approximated using simple interrupted sutures (5-0 black braided silk, Ethicon, USA) (Fig. 12). Coe-Pak is given. Antibiotics and analgesics were advised after surgery. After satisfactory wound healing, the sutures were removed after a week and the mini-implant was loaded for function (Fig. 13).

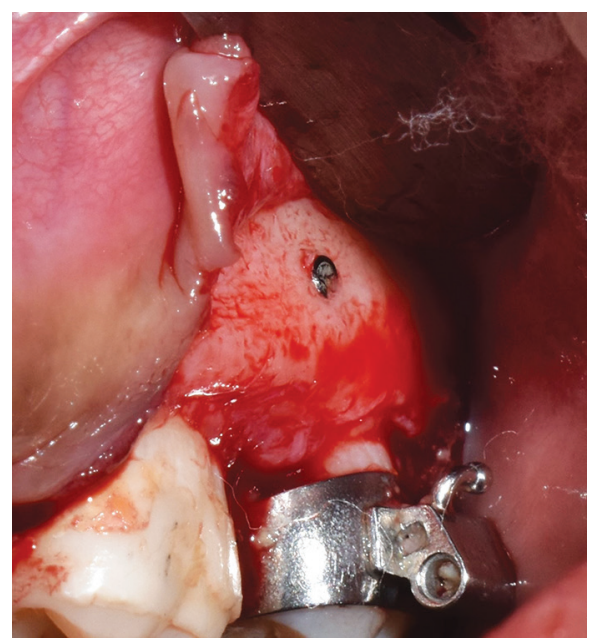

Fig. 9: Fractured mini-implant in relation to 26, 27 regions

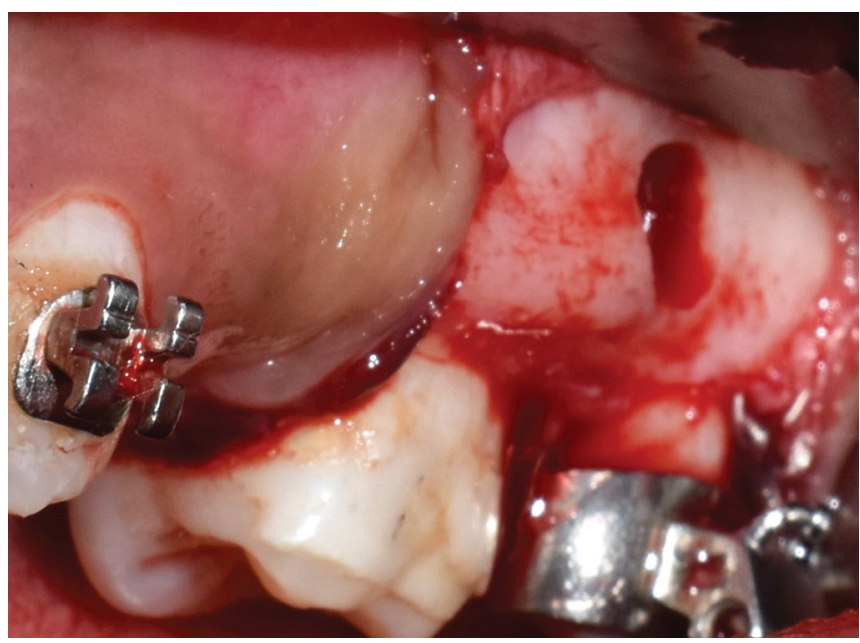

Fig. 10: One millimeter of bone was circumferentially removed around TAD with a carbide bur 


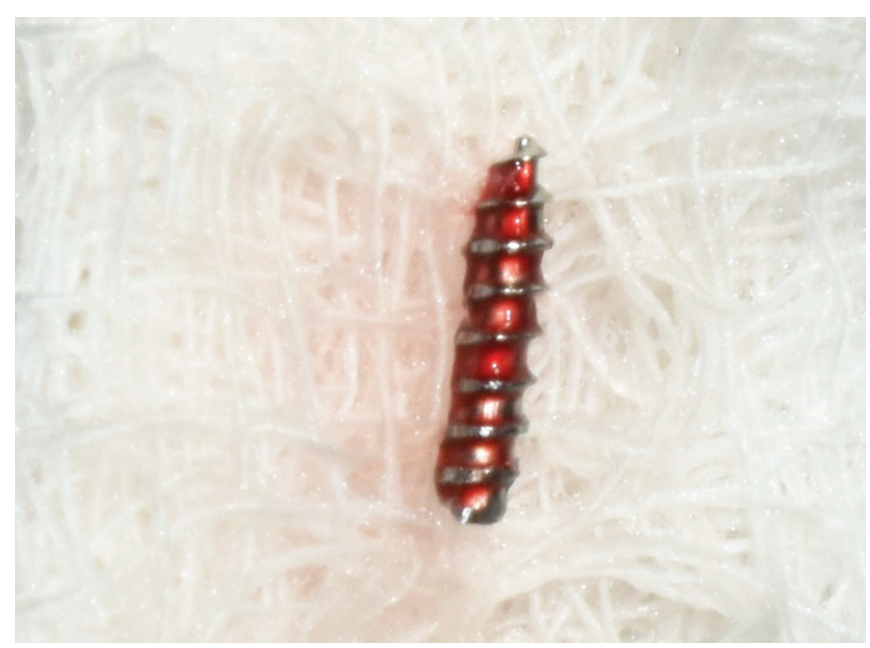

Fig. 11: Retrieved mini-implant

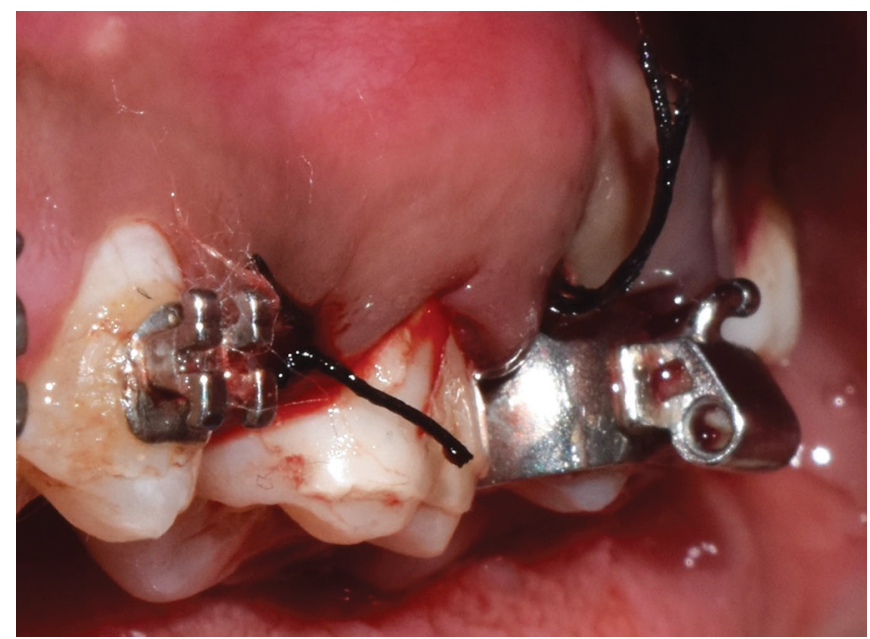

Fig. 12: Simple interrupted suturing is done in relation to 26,27

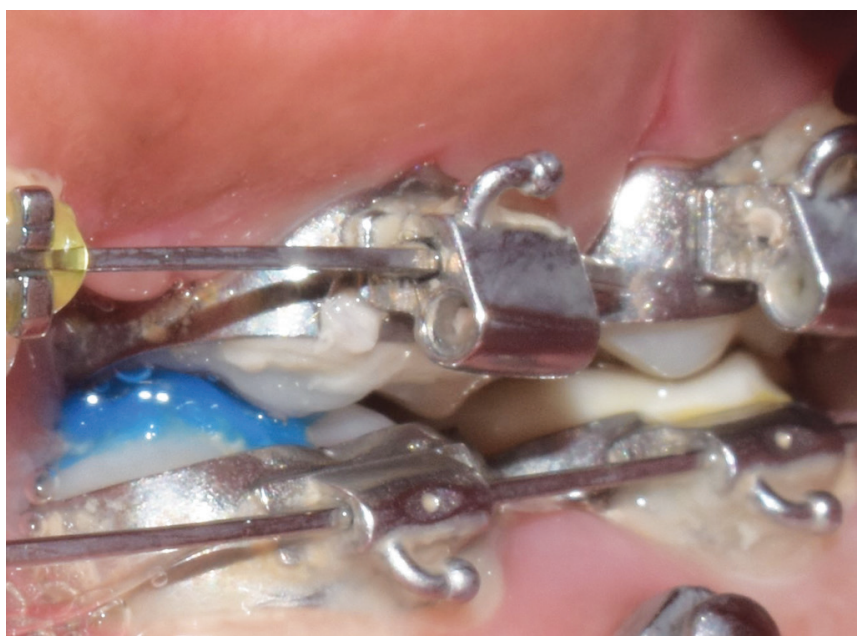

Fig. 13: Postoperative healing after 1 week

\section{Discussion}

Anchoraging system is a solution for the clinicians who prefer to move teeth without undesirable outcomes. ${ }^{4}$ Anchoraging systems like mini-implant act as indirect skeletal anchors, which can provide a range of various tooth movements. Anchoraging device can provide a consistent force to move teeth in the desired position.

The ease of use of anchoring devices has led to their injudicious use. The loss of primary or secondary stability, inadequate bone for placement, risk of infection, soft tissue impingement, and fracture are some of the commonly experienced problems. ${ }^{5,6}$ This type of drawback can be minimized by assessing the implant material, dimensions, and bone-soft tissue biology. Based on the thread design, anchoraging devices can be classified into two. They are drill-free and non-drill-free. Pilot hole preparation is not required for drill-free before insertion, whereas the non-drill-free feature usually requires a soft tissue punch and a pilot hole preparation to be drilled in bone before placement. Several factors that affect the amount of torque employed during insertion are the type of bone present, quality of bone, size of the pilot hole, thread design, and insertion technique. ${ }^{7}$ Barros et al. stated that anchoraging devices with a diameter less than $1.5 \mathrm{~mm}$ are more prone to fracture. ${ }^{8}$ Butcher et al. stated that $4 \%$ of the incidence of fracture is anticipated during the placement of anchoraging devices. ${ }^{9}$ Suzuki et al. figured out that frequency and the incidence of fracture and torque values were directly proportional. ${ }^{10}$ Mischkowski et al. also observed $9.5 \%$ of the incidence of fracture during insertion with the torques ranging from 52 to $56 \mathrm{~N} \mathrm{~cm} .{ }^{11}$ The following precautions are to be followed to avoid fracture of mini-implant-(1) the use of pilot drills when tough resistance is accomplished during placement, (2) the use of torque measuring devices, and (3) evaluation of bone density by using the cone-beam computed tomography scan, which is very much essential for treatment planning while the placement of anchoraging devices. The ideal range of torque is $5-10 \mathrm{~N} \mathrm{~cm}$ and the values exceeding $10 \mathrm{~N} \mathrm{~cm}$ resulted in the fracture of TAD. ${ }^{12}$ The choice of whether to or not to remove the fractured mini-implants depends on the site and location of the fracture, the patient's willingness, and their consent. If it is decided not to remove the fractured mini-implant, periodic evaluation is compulsory. If the stump or end of the fractured mini-implant stump is visible, a notch can be prepared to hold a screwdriver and unscrew it. If the end of the fracture mini-implant is not visible, with the help of a carbide or trephine bur it is removed surgically with generous saline irrigation, which is considered to be a less-invasive approach, as described in this case report.

\section{Conclusion}

Mini-screws are valuable possessions that improve the quality of orthodontic treatment outcomes if used properly. There are only few reported clinical scenarios of this nature. The above-described case reports describe the successful management of fractured mini-implant removal. Mini-implant fracture, even though is a rare clinical chance of occurrence, has to be managed carefully. A thorough understanding and knowledge of biological and mechanical aspects of anchoraging systems would be necessary to avoid further complications.

\section{Clinical Significance}

The case of mini-implant placement and retrieval should be approached with the utmost care, adequate clinical knowledge, and expertise of the operating clinician. The choice of the clinician whether or not to remove fractured mini-implant depends on the site and location of the fracture, the patient's willingness, and consent. 


\section{References}

1. Kuroda S, Tanaka E. Risks and complications of miniscrew anchorage in clinical orthodontics. Japanese Dent Sci Rev 2014;50(4):79-85. DOI: 10.1016/j.jdsr.2014.05.001.

2. Hutton JE, Heath MR, Chai JY, Harnett J, Jemt T, Johns RB, et al. Factors related to success and failure rates at 3-year follow-up in a multicenter study of overdentures supported by Brånemark implants. Int J Oral Maxillofac Implants 1995;10(1).

3. Jaffin RA, Berman CL. The excessive loss of Branemark fixtures in type IV bone: a 5-year analysis. J Periodontol 1991;62(1):2-4. DOI: 10.1902/ jop.1991.62.1.2.

4. Creekmore TD. The possibility of skeletal anchorage. J Clin Orthod 1983;17(4):266-269.

5. Park HS, Jeong SH, Kwon OW. Factors affecting the clinical success of screw implants used as orthodontic anchorage. Am J Orthod Dentofacial Orthop 2006;130(1):18-25. DOI: 10.1016/ j.ajodo.2004.11.032.

6. Cheng SJ, Tseng IY, Lee JJ, Kok SH. A prospective study of the risk factors associated with failure of mini-implants used for orthodontic anchorage. Int J Oral Maxillofac Implants 2004;19(1):100-106.

7. Ansell RH, Scales JT. A study of some factors which affect the strength of screws and their insertion and holding power in bone. J Biomech 1968;1(4):279-302. DOI: 10.1016/0021-9290(68)90023-7.
8. Barros SE, Janson G, Chiqueto K, Garib DG, Janson M. Effect of mini-implant diameter on fracture risk and self-drilling efficacy. Am J Orthod Dentofacial Orthop 2011;140(4):e181-e192. DOI: 10.1016/ j.ajodo.2011.06.016.

9. Büchter A, Wiechmann D, Koerdt S, Wiesmann HP, Piffko J, Meyer U. Load-related implant reaction of mini-implants used for orthodontic anchorage. Clin Oral Implants Res 2005;16(4):473-479. DOI: 10.1111/j.1600-0501.2005.01149.x.

10. Suzuki EY, Suzuki B. Placement and removal torque values of orthodontic miniscrew implants. Am J Orthod Dentofacial Orthop 2011;139(5):669-678. DOI: 10.1016/j.ajodo.2010.11.017.

11. Mischkowski RA, Kneuertz P, Florvaag B, Lazar F, Koebke J, Zöller JE. Biomechanical comparison of four different miniscrew types for skeletal anchorage in the mandibulo-maxillary area. Int J Oral Maxillofac Surg 2008;37(10):948-954. DOI: 10.1016/ j.ijom.2008.07.017.

12. Motoyoshi M, Hirabayashi M, Uemura M, Shimizu N. Recommended placement torque when tightening an orthodontic mini-implant. Clin Oral Implants Res 2006;17(1):109-114. DOI: 10.1111/j.16000501.2005.01211.x. 